Publish Supporting Information

\title{
Straightforward Synthesis of Diverse Nickel Dithiolene Complexes Appended with Hydrogen Bond Donor/Acceptor Groups
}

\author{
Stéphane A. Baudron, Narcis Avarvari* and Patrick Batail*
}

Chimie, Ingénierie Moléculaire et Matériaux d'Angers (CIMMA), UMR 6200 CNRS-Université d'Angers, Bâtiment K, 2 Boulevard Lavoisier, 49045 Angers (France), narcis.avarvari@univ-angers.fr, patrick.batail@univ-angers.fr

\section{Experimental details}

X-Ray diffraction studies: Data were collected on an imaging plate diffraction system (IPDS-Stoe). The structure were solved by direct methods and refined against $F^{2}$ using SHELXL-97. The H atoms were introduced at calculated positions and not refined.

\section{Synthesis}

$\left(\mathbf{P P h}_{4}\right)_{2}\left[\mathbf{N i}(\mathbf{m i d t})_{2}\right]$ : To a solution of sodium methanolate $(0.23 \mathrm{~g} \mathrm{Na}$ in $40 \mathrm{~mL}$ of $\mathrm{MeOH}), 4,5$-Diamido2-oxo-1,3-dithiole $(0.50 \mathrm{~g}, 2.45 \mathrm{mmol})$ is added under nitrogen. The solution then turns dark red as the dithiocarbonate goes into solution. After one hour, $\mathrm{Ni}\left(\mathrm{NO}_{3}\right)_{2}, 6 \mathrm{H}_{2} \mathrm{O}(0.36 \mathrm{~g}, 1.23 \mathrm{mmol})$ is added. The solution becomes green-brown and a brown precipitate appears. After three hours, the precipitate is filtered off and washed with dry $\mathrm{MeOH}$ until the solution is colorless. The filtrate and the $\mathrm{MeOH}$ washings are then combined and tetraphenylphosphonium bromide $(1.10 \mathrm{~g}, 2.62 \mathrm{mmol})$ is added. The resulting shiny black precipitate is filtered off and recrystallized from hot acetonitrile affording large black prisms Yield: $0.69 \mathrm{~g}(51.3 \%)$. IR (KBr, v/cm $\left.{ }^{-1}\right)$ : $1681(\mathrm{C}=\mathrm{O}), 1703(\mathrm{C}=\mathrm{O})$. Anal. Calcd for $\mathrm{C}_{58} \mathrm{H}_{45} \mathrm{~N}_{3} \mathrm{O}_{4} \mathrm{P}_{2} \mathrm{~S}_{4} \mathrm{Ni}: \mathrm{C}$ 63.45; H 4.10, N 3.83. Found; C 63.04, H 4.05, N 3.71.

$\left(\mathbf{P P h}_{4}\right)\left[\mathrm{Ni}(\mathbf{m i d t})_{2}\right]$ : Addition of iodine $(0.06 \mathrm{~g})$ to a solution of $\left(\mathrm{PPh}_{4}\right)_{2}\left[\mathrm{Ni}(\mathrm{midt})_{2}\right](0.50 \mathrm{~g}, 0.46 \mathrm{mmol})$ in methanol $(120 \mathrm{~mL})$ provokes a color change from green to brown. The solution is stirred for 3 hours and evaporated to dryness. The resulting solid is thoroughly washed with water and ether and then recrystallized from acetonitrile yielding black prisms Yield: $0.25 \mathrm{~g}(75 \%)$. IR $\left(\mathrm{KBr}, \mathrm{v} / \mathrm{cm}^{-1}\right): 1732$ $(\mathrm{C}=\mathrm{O}), 1750(\mathrm{C}=\mathrm{O})$. Anal. Calcd for $\mathrm{C}_{32} \mathrm{H}_{22} \mathrm{~N}_{2} \mathrm{O}_{4} \mathrm{PS}_{4} \mathrm{Ni}$ : C 53.65; H 3.09, N 3.91. Found: C 53.11, $\mathrm{H}$ 3.21, N 3.82 . 
$\left(\mathbf{P P h}_{4}\right)\left[\mathrm{Ni}(\mathbf{m a d t})_{2}\right]:$ To a solution of sodium methanethiolate $(0.34 \mathrm{~g}, 4.90 \mathrm{mmol})$ in $\mathrm{MeOH}(30 \mathrm{~mL})$ 4,5-Diamido-2-oxo-1,3-dithiole (0.50 g, $2.45 \mathrm{mmol})$ is added under nitrogen. The solution slowly turns orange. After 3 hours, $\mathrm{Ni}\left(\mathrm{NO}_{3}\right)_{2}, 6 \mathrm{H}_{2} \mathrm{O}(0.36 \mathrm{~g}, 1.23 \mathrm{mmol})$ is added and the mixture is stirred for 5 hours. The solution is filtered, and the solid is washed with dry $\mathrm{MeOH}$. The filtrate and the washings are combined and tetraphenylphosphonium bromide $(1.02 \mathrm{~g}, \mathrm{mmol})$ in $\mathrm{MeOH}$ is added. The solution is concentrated to a volume of $10 \mathrm{~mL}$ and filtered. The black solid is washed with water and ether and then extracted with methanol and dried under vacuum to yield a crystalline black powder Yield: $0.45 \mathrm{~g}$ (48\%). IR ( KBr, v/cm $\left.{ }^{-1}\right): 1640(\mathrm{C}=\mathrm{O})$. Slow diffusion of $\mathrm{CHCl}_{3}$ into a solution of complex in DMSO afforded black crystals of $\mathbf{3}^{-}$. Unfortunately, due to the presence of crystallization solvent within the crystals, elemental analysis was not accurate enough for this complex.

$\left(\mathbf{P P h}_{4}\right)\left[\mathrm{Ni}(\text { mant })_{2}\right]:\left(\mathrm{PPh}_{4}\right)\left[\mathrm{Ni}\left(\mathrm{madt}_{2}\right](0.25 \mathrm{~g}, 0.33 \mathrm{mmol})\right.$ was heated under reflux in $\mathrm{MeOH}$ for a period of $24 \mathrm{~h}$, then, upon slow cooling, small black shiny platelets of 4 crystallized out from the solution. Yield: $0.18 \mathrm{~g}(75 \%)$. IR $\left(\mathrm{KBr}, v / \mathrm{cm}^{-1}\right): 1611(\mathrm{C}=\mathrm{O}), 2202(\mathrm{C} \equiv \mathrm{N})$. Anal. Calcd for $\mathrm{C}_{32} \mathrm{H}_{24} \mathrm{~N}_{4} \mathrm{O}_{2} \mathrm{PS}_{4} \mathrm{Ni}$ : C 53.79, H 3.38, N 7.84. Found: C 53.43, H 3.53, N 7.68.

$\left(\mathrm{Bu}_{4} \mathbf{N}\right)_{2}\left[\mathbf{N i}(\mathbf{m i d t})_{2}\right]$ : To a solution of sodium methanolate $(0.23 \mathrm{~g} \mathrm{Na}$ in $40 \mathrm{~mL}$ of $\mathrm{MeOH}), 4,5-$ Diamido-2-oxo-1,3-dithiole $(0.50 \mathrm{~g}, 2.46 \mathrm{mmol})$ is added under nitrogen. The solution then turns dark red as the dithiocarbonate goes into solution. After one hour, $\mathrm{Ni}\left(\mathrm{NO}_{3}\right)_{2}, 6 \mathrm{H}_{2} \mathrm{O}(0.36 \mathrm{~g}, 1.23 \mathrm{mmol})$ is added. The solution becomes green-brown and a brown precipitate appears. After three hours, the precipitate is filtered off and washed with dry $\mathrm{MeOH}$ until the solution is colorless. The filtrate and the $\mathrm{MeOH}$ washings are then combined and tetrabutylammonium bromide $(0.90 \mathrm{~g}, 2.8 \mathrm{mmol})$ is added. The solution is concentrated and upon addition of water $(100 \mathrm{~mL})$ a green precipitate is produced. Recrystallization from hot acetone affords large black rods. Yield: 568 mg (53.7\%). Anal. Calcd for $\mathrm{C}_{40} \mathrm{H}_{74} \mathrm{~N}_{4} \mathrm{O}_{4} \mathrm{~S}_{4} \mathrm{Ni}$ : C 55.73, H, 8.65, N, 6.50. Found: C 55.32, H 8.59, N 6.51.

$\left(\mathrm{Bu}_{4} \mathbf{N}\right)\left[\mathrm{Ni}(\mathbf{m i d t})_{2}\right]$ : Addition of iodine $(0.06 \mathrm{~g})$ to a solution of $\left(\mathrm{Bu} \mathrm{H}_{4} \mathrm{~N}\right)_{2} \mathrm{Ni}(\mathrm{midt})_{2}(0.40 \mathrm{~g}, \mathrm{mmol})$ in methanol $(120 \mathrm{~mL})$ provokes a color change from green to brown. The solution is stirred for 3 hours and evaporated to dryness. The resulting solid is thoroughly washed with water and ether and the recrystallized from acetone yielding green crystals that desolvate upon air-exposure. Anal. Calcd for $\mathrm{C}_{24} \mathrm{H}_{38} \mathrm{~N}_{3} \mathrm{O}_{4} \mathrm{~S}_{4} \mathrm{Ni}: \mathrm{C} 46.53, \mathrm{H}$ 6.14, N 6.78. Found: C 47.14, H 6.57, N 6.45.

$\left(\mathrm{Bu}_{4} \mathbf{N}\right)_{2}\left[\mathrm{Ni}(\operatorname{mant})_{2}\right]$ : Electrocrystallization of a solution of $\left(\mathrm{Bu}_{4} \mathrm{~N}\right)\left[\mathrm{Ni}(\operatorname{mant})_{2}\right]$, obtained similarly as $\left(\mathrm{PPh}_{4}\right)\left[\mathrm{Ni}(\text { mant })_{2}\right]$ by replacing $\mathrm{PPh}_{4} \mathrm{Cl}$ with $\mathrm{Bu}_{4} \mathrm{NBr}$, in THF/MECN (1/1) at a constant current of 0.5 $\mu \mathrm{A}$ afforded after one week red crystalline platelets of $\mathbf{4}^{2-}$. IR $\left(\mathrm{KBr}, v / \mathrm{cm}^{-1}\right): 1580(\mathrm{C}=\mathrm{O}), 2187(\mathrm{C} \equiv \mathrm{N})$. 
Figure S1. Channel structure in $\left(\mathrm{Bu}_{4} \mathrm{~N}\right)_{2} \mathrm{Ni}(\mathrm{midt})_{2},\left(\mathrm{PPh}_{4}\right)_{2} \mathrm{Ni}(\text { midt })_{2} \cdot \mathrm{CH}_{3} \mathrm{CN},\left(\mathrm{PPh}_{4}\right) \mathbf{N i}(\text { midt })_{2}$ (from top to bottom).
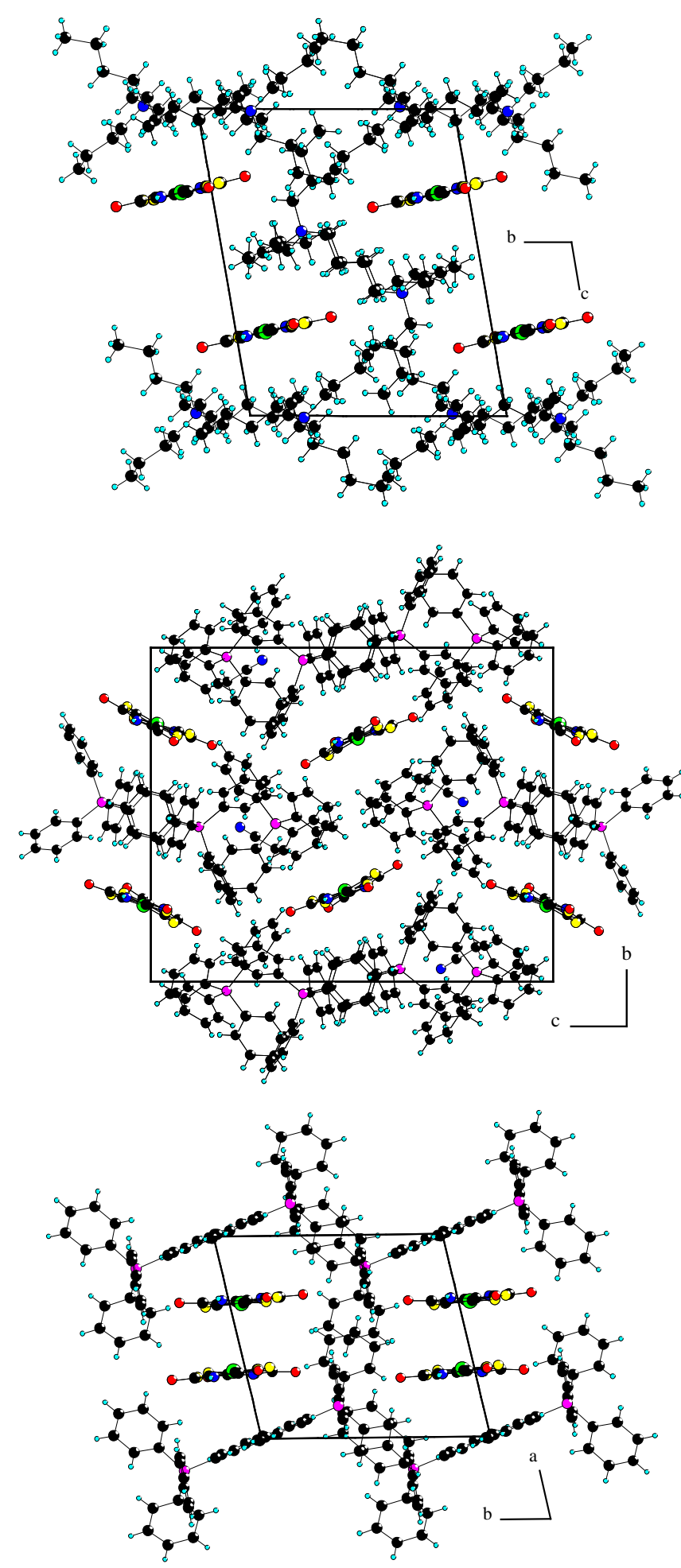
Figure S2. Hydrogen bond ribbons formed through the $\mathrm{R}_{2}{ }^{2}(8)$ motif in the structure of $\left(\mathrm{Bu}_{4} \mathrm{~N}\right)_{2}\left[\mathrm{Ni}(\text { mant })_{2}\right]$.

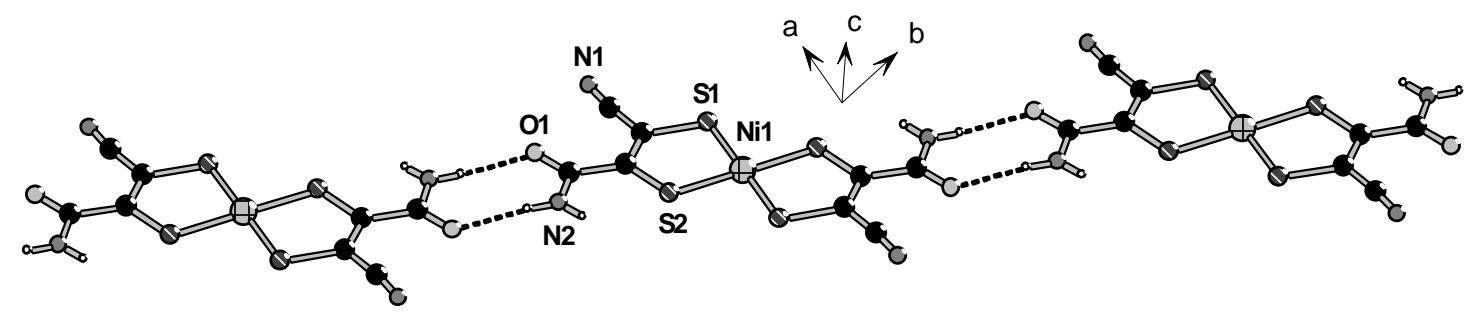


Figure S3. Temperature dependence of the magnetic susceptibility of $\left[\mathrm{PPh}_{4}\right]\left[\mathrm{Ni}(\text { midt })_{2}\right]$, as measured in an applied field of $5000 \mathrm{G}$ on a sample of $13.09 \mathrm{mg}$. The circles represent experimental data and the solid line represents the calculated fit to the data with $g=2.057, \alpha=0.72, \mathrm{~J} / \mathrm{k}=83 \mathrm{~K}$ and $\chi_{0}=$ 1.6.10 cgsu.mol ${ }^{-1}$ and $\mathrm{C}=0.023 \mathrm{~cm}^{3} \cdot \mathrm{K}^{-4} \mathrm{~mol}^{-1}$ using the equation $\chi=\chi_{0}+\frac{\mathrm{C}}{\mathrm{T}}+\frac{\mathrm{Ng}^{2} \mu_{\mathrm{B}}^{2}}{\mathrm{kT}} \frac{\mathrm{A}+\mathrm{B}\left(\frac{|\mathrm{J}|}{\mathrm{kT}}\right)+\mathrm{C}\left(\frac{|\mathrm{J}|}{\mathrm{kT}}\right)^{2}}{1+\mathrm{D}\left(\frac{|\mathrm{J}|}{\mathrm{kT}}\right)+\mathrm{E}\left(\frac{|\mathrm{J}|}{\mathrm{kT}}\right)^{2}+\mathrm{F}\left(\frac{|\mathrm{J}|}{\mathrm{kT}}\right)^{3}}$ where

$\mathrm{A}=0.25$

$\mathrm{B}=-0.068475+0.131935 \alpha$

$\mathrm{C}=0.00425623-0.03167 \alpha+0.12278 \alpha^{2}-0,29943 \alpha^{3}+0,21814 \alpha^{4}$

$\mathrm{D}=0.035255+0.65210 \alpha$

$\mathrm{E}=-0.00089418-0.10209 \alpha+0.872155 \alpha^{2}-0.18472 \alpha^{3}$

$\mathrm{F}=0.045230-0.0081910 \alpha+0.83234 \alpha^{2}-2.6181 \alpha^{3}+1.92813 \alpha$

developed by Hatfield and coworkers (Hall, J.; Marsh, W. ; Weller, R. R. ; Hatfield, W. E., Inorg. Chem., 1981, 20, 1033).

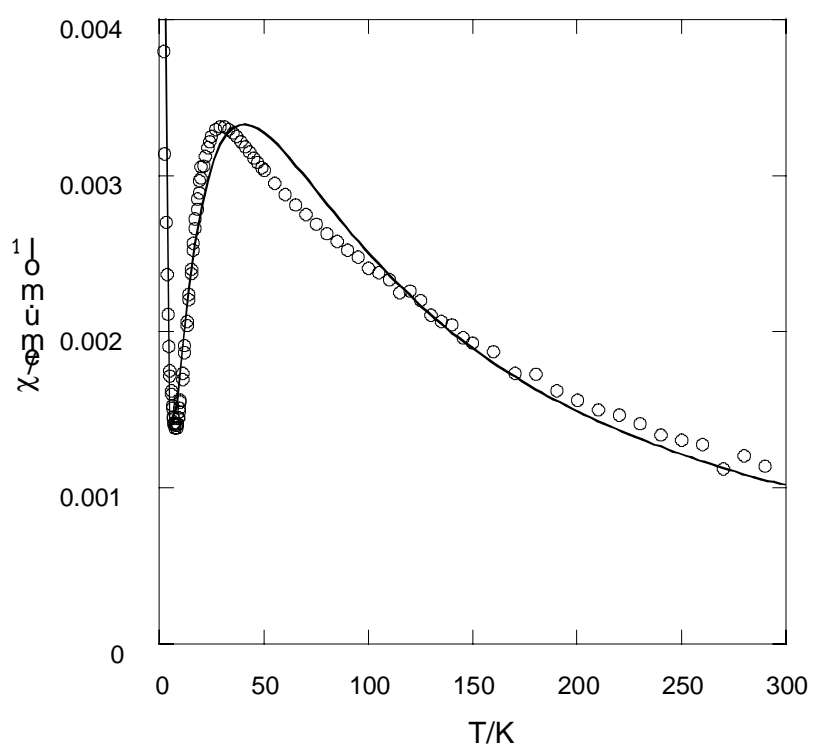

